\title{
Effect of Time on Sensitivity and Specificity of Access Flow in Predicting Thrombosis
}

\author{
William F. Weitzel, Jonathan H. Segal, Sean F. Leavey, Rajiv Saran, Richard D. Swartz, \\ and Joseph M. Messana \\ Department of Internal Medicine, Division of Nephrology, University of Michigan, Ann Arbor, Michigan
}

\begin{abstract}
Dialysis access monitoring may help decrease thrombosisrelated morbidity. We investigated the effect of time elapsed since an access flow measurement on test accuracy of a novel flow monitoring method called variable flow (VF) Doppler. A retrospective review was conducted in 36 patients with prosthetic grafts for vascular access using access thrombosis as the clinical endpoint. Receiver operator characteristic (ROC) curves and test sensitivity and specificity were determined for various follow-up time intervals. ROC analysis showed increasing test discrimination for shorter time intervals. Sensitivity and specificity

for a commonly used surveillance threshold $(600 \mathrm{ml} / \mathrm{min})$ showed specificity that was little changed (88-93\%) from follow-up time intervals of 15 days to 6 months. However, sensitivity was low $(21 \%)$ at 6 months, increased to $50 \%$ at 2 months, $67 \%$ at 1 month, and $100 \%$ at 15 days (a single event). Low access blood flow using VF Doppler predicts near-term thrombosis. These data further imply that the discriminative value of access flow monitoring appears to be highly dependent on time from the flow measurement, improving with shorter time intervals from the measurement.
\end{abstract}

Dialysis access remains a major cause of morbidity among dialysis patients and a frequent cause for hospitalization $(1,2)$. The National Kidney Foundation Dialysis Outcomes Quality Initiative guidelines (NKFDOQI) as well as many researchers and clinicians have advocated access surveillance as a means to improve patient care and reduce access-related costs (3-5). Several techniques have been developed for access surveillance. These methods include duplex ultrasound techniques (6-9), static and dynamic access pressure monitoring (9-12), recirculation (13), and indicator dilution techniques (14-18). A method that measures access blood flow using a changing Doppler signal as a function of blood flow rate in the access during dialysis without the need for duplex imaging is also being evaluated (19-22).

An ideal access monitoring test would predict nearly all patients who will develop thromboses (i.e., be highly sensitive) without falsely predicting thrombosis in those who will not develop thromboses (i.e., be highly specific). Even though access blood flow rate appears to predict progression of access stenoses and allows for timely intervention to prevent thrombosis $(3,6-8,18)$, at least in some patient populations access flow seems to lack sufficient accuracy to aid the access

Address correspondence to: William F. Weitzel, MD, 3914 Taubman Center, 1500 E. Medical Center Dr. , Ann Arbor, Ml 48109-0364, or e-mail: weitzel@umich.edu.

Seminars in Dialysis-Vol 16, No 6 (November-December) 2003 pp. 498-501 monitoring process $(23,24)$. Access blood flow appears to have varying degrees of combined sensitivity and specificity in predicting access thrombosis in an analysis comparing several studies (23). While it is clear that there may be many patient- and populationdependent variables that influence access thrombosis in addition to access blood flow, the influence of the follow-up time period from the flow measurement has not been systematically studied.

We used the variable flow (VF) Doppler method (19-22) to determine access flow. We used ROC analysis, comparing areas under the receiver operator characteristic (ROC) curve, to investigate the effect of duration of follow-up time from a single access flow measurement in determining the risk of subsequent thrombosis. In ROC curve analysis, a test with an area under the curve (AUC) of 0.5 does not discriminate between patients who will have an event and those who will not. An AUC of 1.0 represents a test that perfectly discriminates between those who will have an event and those who will not (23).

In addition to comparing the AUC for different ROC curves across the entire range of observed blood flow rates, the effect of follow-up time duration on a surveillance threshold $(600 \mathrm{ml} / \mathrm{min})$ in predicting thrombosis was also evaluated. This was done by determining the sensitivity and specificity of a flow measurement less than $600 \mathrm{ml} / \mathrm{min}$ to predict access thrombosis for follow-up intervals ranging from 15 to 180 days. 
Methods

\section{Measurement Procedure}

The VF Doppler method has been outlined in previous studies $(19,21,22)$. Briefly, the dialysis pump induced change in the Doppler signal between the needles is used to determine the access blood flow without the need for cross-sectional area measurement or duplex imaging. The Doppler transducer is placed between the needles and the Doppler signal is measured as a function of dialysis blood pump speed. A linear regression algorithm is used to determine access flow from these measurements. A spectral Doppler PC board and software (SPECS USA, Sarasota, FL), which allow calculation and export of various spectral waveform parameters, including the instantaneous mean and time-averaged mean Doppler signals was connected to a laptop computer for signal analysis and access flow determination.

\section{Patients}

A retrospective record review of 36 patients with prosthetic bridge grafts was conducted at the University of Michigan Medical Center's Outpatient Hemodialysis Facility after Investigational Review Board approval at our institution. All patients who had a VF Doppler measurement and who consented to medical record review (36 of 39) were included in the analysis for the 6-month period starting August 1, 2000. In order to avoid potential selection bias, an access thrombosis was defined as the event and not stenosis without thrombosis. Patients who underwent angiography with or without angioplasty at the discretion of their primary nephrologist were included in the study. For patients who had multiple VF Doppler measurements, the first measurement after August 1, 2000, was used. Patients were followed for up to 180 days or until their first access thrombosis (event) within the study time period, or until lost from our dialysis unit (e.g., transplant, death, relocation). Patients were dialyzed with Fresenius 2008H (Fresenius Medical Care, Lexington, MA) and Cobe Century System 3 (Gambro Renal Care Products, Lakewood, CO) with 15 -gauge dialysis needles.

\section{Data Analysis}

The number of events (thromboses) was determined at $15,30,60,90,120,150$, and 180 days from the first VF Doppler measurement in the study interval. The ROC curves were determined across the range of access blood flow rates for each of these follow-up intervals. The AUC was determined for each ROC curve. The $p$-value represents the probability that an AUC different from the null hypothesis (AUC of 0.5) may have occurred by random chance. The sensitivity and specificity were then determined at each follow-up interval for thromboses occurring below the suggested threshold access flow value of $600 \mathrm{ml} / \mathrm{min}$. Values were calculated using SPSS software (SPSS for Windows, Release 10.0.5; SPSS Inc., Chicago, IL).

\section{Results}

Follow-up time from measurement in days, number of patients with thromboses, total number $(n)$ of patients followed until that time interval, and thrombosis rates, along with the AUC for the ROC curve and $p$-value for the AUC are shown in Table 1. The AUC increased as follow-up time decreased for all follow-up time intervals in the ROC analysis, indicating improved test discrimination for shorter time intervals. The $p$-value became significant $(p<0.05)$ at 3 and 2 months, but increased again at the shortest time intervals ( 15 and 30 days), since the number of events in this cohort at shorter time intervals were few.

Combined sensitivity and $1-$ specificity are shown in the form of ROC curves in Fig. 1 for 60 days follow-up time (the greatest AUC that maintained a $p$-value less than 0.05) compared with 180 days (the longest followup time interval studied). Fig. 2 shows the sensitivity and specificity for a commonly used access flow value of 600 $\mathrm{ml} / \mathrm{min}$ as a function of the different follow-up time intervals (third-order polynomial curve fitted to data points). Results evaluating the effect of time on the sensitivity and specificity for this commonly used surveillance threshold showed specificity was little

TABLE 1. Summary of thrombosis rates and ROC curve data

\begin{tabular}{lccccc}
\hline $\begin{array}{l}\text { Time } \\
\text { (days) }\end{array}$ & Thromboses & $\begin{array}{c}\text { Total } \\
\text { no. }\end{array}$ & $\begin{array}{c}\text { Thrombosis } \\
\text { rate }(\%)\end{array}$ & AUC & $p$ \\
\hline 15 & 1 & 36 & 2.78 & 1.00 & 0.09 \\
30 & 3 & 36 & 8.33 & 0.83 & 0.06 \\
60 & 4 & 36 & 11.11 & 0.82 & 0.04 \\
90 & 7 & 35 & 20.00 & 0.79 & 0.02 \\
120 & 8 & 35 & 22.86 & 0.71 & 0.08 \\
150 & 8 & 33 & 24.24 & 0.70 & 0.10 \\
180 & 14 & 29 & 48.28 & 0.60 & 0.38 \\
\hline
\end{tabular}

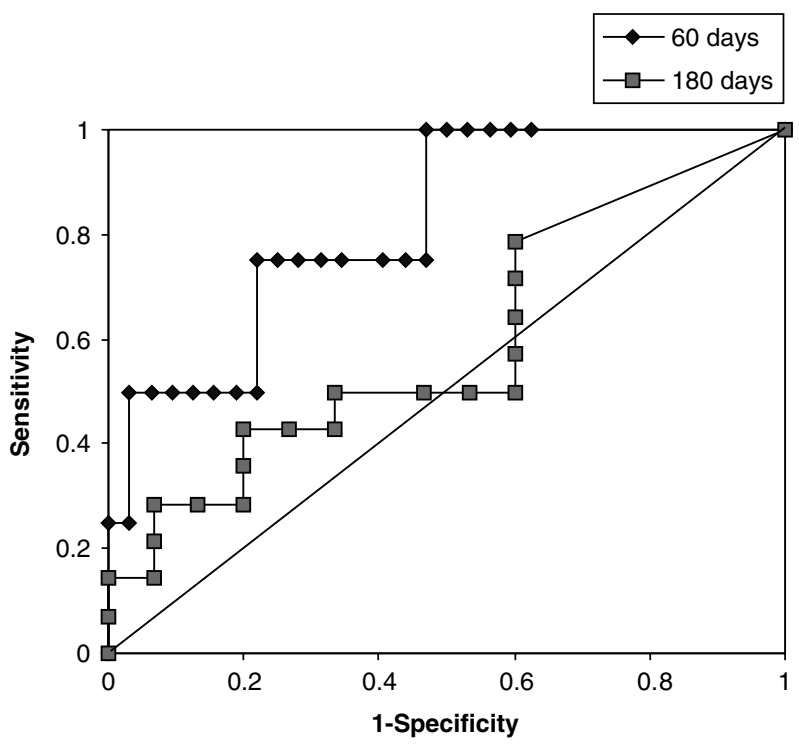

FIG. 1. ROC curves for 60 and 80 days. 


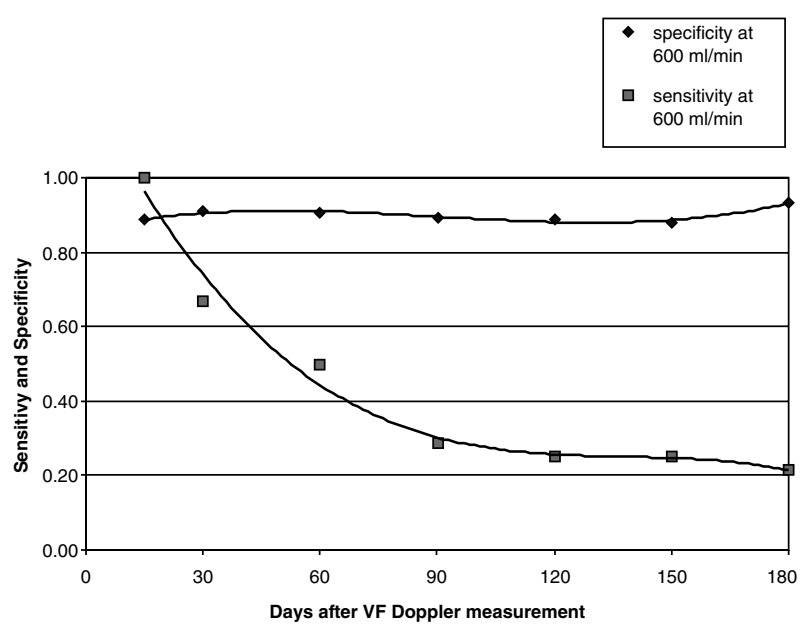

FIG. 2. Sensitivity and specificity of $600 \mathrm{ml} / \mathrm{min}$ access flow in predicting thrombosis as a function of time.

changed ( $88 \%$ to $93 \%$ ) for follow-up time intervals from 15 days to 6 months. However, using this threshold value, sensitivity was low (21\%) at 6 months, increased to $50 \%$ at 2 months, $67 \%$ at 1 month, and $100 \%$ at 15 days (a single event).

\section{Discussion}

The results of this analysis need to be considered conceptually in the context of the likely relationship between access flow and thrombosis. Low access flow likely results from many factors. Venous outflow stenosis is commonly thought to be the major entity responsible for low flow and increased thrombosis risk. However, access flow is variable and likely influenced by other dynamic anatomic and nonanatomic factors in addition to a venous outflow stenosis $(24,25)$. Nonetheless, low flow appears to be a risk factor for thrombosis $(3,6-8,18)$, and declining access flow may also predict thrombosis (26).

A graft thrombosis is associated with a decrease in graft blood flow from some starting value to zero over some time interval. When thrombosis occurs with initially high flow states, a flow reduction occurring over seconds, minutes, or hours (significantly less than the time it takes to schedule a corrective procedure) is too abrupt to permit flow monitoring to help prevent thrombosis. This may well be the case in the patient who sleeps on their access arm, or who has other independent (non-flow-related) risk factors for thrombosis.

On the other hand, when reduced access flow declines over a longer period of time, then it may be useful in predicting thrombosis. These data suggest that access flow may contribute to the prediction of thrombosis for up to several months; however, it is increasingly predictive as the follow-up time from the measurement decreases. In other words, low access flow is most predictive of those who will clot in the near future but not the distant future.
Given the high incidence of graft thrombosis with its high morbidity and cost $(1,2,5)$, it is important to optimize sensitivity while maintaining specificity for surveillance programs. An important finding is that while specificity remained little changed from 15 to 180 days, the sensitivity showed a marked increase as the follow-up interval was shortened. It may also be that access flow can contribute to risk assessment for thrombosis over longer time intervals; however, this will likely require its use in conjunction with other comorbidities that may aid in the assessment of longer-term risk of thrombosis. These data may partly explain why some studies have failed to show adequate risk stratification using access flow alone (24) and why others have indicated that a decrease in flow heralds thrombosis (26).

In addition, since factors independent of flow may affect the risk of thrombosis, it is likely that different patient populations require monitoring at different intervals in order to achieve desirable sensitivity and specificity. There may be some groups where access flow monitoring is not helpful. Most nephrologists have encountered patients who thrombose repeatedly despite correcting structural abnormalities and maintaining adequate access flow. At the other extreme, patients with grafts who have not thrombosed in years and yet maintain a relatively low access flow may be at lower risk of thrombosis for reasons that are not yet clear. While access flow monitoring may be helpful for this latter group to ensure they receive adequate dialysis, caution must be used to avoid unnecessary procedures for these patients. A better understanding of non-flow-related risk factors for thrombosis is also needed in order to use flow optimally as a monitoring tool.

In conclusion, the discriminative value of access flow monitoring appears to be highly dependent on time from the flow measurement. Low flow predicts near-term thrombosis much better than long-term thrombosis. The monitoring interval should be carefully evaluated in different patient populations in order to establish rational access surveillance protocols.

\section{Acknowledgments}

This research was supported in part by a research grant from the Renal Research Institute and an unrestricted grant from SPECS USA, Inc.

\section{References}

1. Feldman HI, Held PJ, Hutchinson JT, Soiber E, Hartigan MF, Berlin JA: Hemodialysis vascular access morbidity in the United States. Kidney Int 43:1091-1096, 1993

2. Mayers JD, Markell MS, Cohen LS, Hong J, Lundin P, Friedman EA: Vascular access surgery for maintenance hemodialysis: variables in hospital stay. ASAIO J 38:113-115, 1992

3. May RE, Himmelfarb J, Yenicesu M, Knights S, Ikizler TA, Schulman G, Hernanz-Schulman M, Shyr Y, Hakim RM: Predictive measures of vascular access thrombosis: a prospective study. Kidney Int 52:1656-1662, 1997

4. Schwab S, Besarab A, Beathard G: Monitoring and maintenance. Am J Kidney Dis 30(suppl 3):S162-S166, 1997 
5. U.S. Renal Data System: The cost effectiveness of alternative types of vascular access and the economic cost of ESRD. Am J Kidney Dis 26:S140-S156, 1995

6. Strauch BS, O'Connell RS, Geoly KL, Grundlehner M, Yakub YN, Teitjen DP: Forecasting thrombosis of vascular access with Doppler color flow imaging. Am J Kidney Dis 19:554-557, 1992

7. Findley DE, Longley DG, Foshager MC, Letourneau JG: Duplex and color sonography of hemodialysis arteriovenous fistulas and grafts. Radiographics 13:983-999, 1993

8. Sands J: The role of color-flow Doppler ultrasound in the management of hemodialysis accesses. ASAIO J 44:41-43, 1998

9. Sullivan KL, Besarab A, Bonn J, Shapiro MJ, Gardiner GA, Moritz MJ Hemodynamics of failing dialysis grafts. Radiology 186:867-872, 1993

10. Besarab A, Sullivan KL, Ross RP, Moritz MJ: Utility of intra-access pressure monitoring in detecting and correcting venous outlet stenosis prior to thrombosis. Kidney Int 47:1364-1373, 1995

11. Besarab A, Frinak S: The prevention of access failure: Pressure monitoring ASAIO J 44:35-37, 1998

12. Schwab SJ, Raymond JR, Saeed M, Newman GE, Dennis PA, Bollinger RR Prevention of hemodialysis fistula thrombosis: early detection of venous stenoses. Kidney Int 36:707-711, 1989

13. Besarab A, Sherman R: The relationship of recirculation to access blood flow. Am J Kidney Dis 29:223-229, 1997

14. Depner TA: Hemodialysis access: in-line methods. ASAIO J 44:38-39, 1998

15. Krivitski NM: Theory and validation of access flow measurement by dilution technique during hemodialysis. Kidney Int 48:244-250, 1995

16. Brosman PJ, Boereboom FTJ, Bakker CJ, Mali WPT, Eikelboom BC, Blankestijn PJ, Koomans HA: Access flow measurements in hemodialysis patients. In vivo validation of an ultrasound dilution technique. $J$ Am Soc Nephrol 7:966-969, 1996
17. Lindsay RM, Bradfield E, Rothera C, Kianfar C, Malek P, Blake PG: A comparison of methods for the measurement of hemodialysis access recirculation and access blood flow rate. ASAIO J 44:62-67, 1998

18. Wang E, Schneditz D, Nepomuceno C, Lavarias V, Martin K, Morris AT, Levin NW: Predictive value of access blood flow in detecting access thrombosis. ASAIO J 44:M555-M558, 1998

19. Weitzel WF, Rubin JM, Swartz RD, Woltmann DJ, Messana JM: Variable flow Doppler for hemodialysis access evaluation. theory and clinical feasibility. ASAIO J 46:65-69, 2000

20. Paun M, Beach K, Ahmad S, Hickman R, Meissner M, Plett C, Strandness E: New ultrasound approaches to dialysis access monitoring. Am J Kidney Dis 35:477-481, 2000

21. Weitzel WF, Khosla N, Rubin JM: Retrograde hemodialysis access flow during dialysis as a predictor of access pathology. Am J Kidney Dis 37:12411246,2001

22. Weitzel WF, Rubin JM, Leavey SF, Swartz RD, Dhingra RK, Messana JM: Analysis of variable flow (VF) Doppler hemodialysis access flow: measurements and comparison with ultrasound dilution. Am J Kidney Dis 38:935940, 2001

23. Paulson WD, Ram SJ, Birk CG, Work J: Does blood flow accurately predict thrombosis or failure of hemodialysis synthetic grafts? A meta-analysis. Am J Kidney Dis 34:478-485, 1999

24. DeSoto DJ, Ram SJ, Faiyaz R, Birk CG, Paulson WD: Hemodynamic reproducibility during blood flow measurements of hemodialysis synthetic grafts. Am J Kidney Dis 37:790-796, 2001

25. Rehman SU, Pupim LB, Shyr Y, Hakim R, Ikizler TA: Intradialytic serial vascular access flow measurements. Am J Kidney Dis 34:471-477, 1999

26. Neyra NR, Ikizler TA, May RE, Himmelfarb J, Schulman G, Shyr Y, Hakim RM: Change in access blood flow over time predicts vascular access thrombosis. Kidney Int 54:1714-1719, 1998

\section{Erratum}

Roberta Braun Curtin, Bryan Becker, Paul L. Kimmel, and Dori Schatell: An Integrated Approach to Care for Patients with Chronic Kidney Disease. Semin Dial 2003;16:399-402.

Due to an inadvertent oversight the abstract was published with a contextual error. The Publisher regrets the error. The following is the corrected abstract.

Although the Kidney Disease Outcomes and Quality Initiative (K/DOQI) guidelines serve to integrate the multiple stages of chronic kidney disease (CKD), in practice, the treatment of kidney disease over its progressive course may be somewhat fragmented. Because the provision of integrated care across the stages of kidney disease is likely to be advantageous for both patients and care providers, a conceptual framework which graphically depicts the complex and chronic nature of kidney disease may prove useful. The Life Options Rehabilitation Advisory Council (LORAC) proposes a cycle diagram to reflect the chronicity and complexity of kidney disease and to emphasize a holistic perception of kidney disease from its inception to the worst-case scenario outcome of kidney failure. The kidney disease cycle conceptualization can serve as a patient teaching aid and as a reminder of the communication, collaboration, and cooperation that are required among primary care physicians and practitioners in each of the specialty areas that address the spectrum of kidney disease. 